\title{
Tape-recording data for a cumulative recorder and for programming interval schedules
}

\author{
ALLEN H. WOLACH, PETER ROCCAFORTE, and STEPHEN E. BREUNING \\ Illinois Institute of Technology. Chicago, Lllinois 60616
}

\begin{abstract}
A simple method for recording discrete events with a cassette tape recorder is described. Since the converter for the recorder is inexpensive, data for several subjects can be recorded simultaneously. The recorder-converter can also be used to program interval schedules. Cassette recorded responses for a subject can be played into a cumulative recorder.
\end{abstract}

The purpose of this paper is to describe an inexpensive cassette tape recorder that can be used to record responses. The cassette recording can later be played into a cumulative recorder to make a cumulative record for a subject. If a cumulative recorder is not immediately available, it is possible to record data from a subject and to save the recording until a later time. Indeed, one cumulative recorder can be used to produce records for subjects that were run at the same time. Reliable cumulative recorders cost over $\$ 300$; a cassette recorder can be obtained for under $\$ 20$. The components necessary for converting a cassette device into a response recorder and for converting the output from the recorder into a relay closure cost less than $\$ 6$. The converter does not modify ordinary functioning of the recorder so the unit can be used as an ordinary cassette recorder when needed. This recorder-converter system can be adapted for programming interval schedules.

\section{HARDWARE AND METHOD}

Figure 1 shows the circuit used for recording a subject's responses. A transformer (T1) steps down the line voltage from $110 \mathrm{~V}$ to $6.3 \mathrm{~V}$. Two diodes, D1 and D2 (IN4001), change the sine wave into a square wave. The 12,000-ohm .5-W resistor (R1) serves as a limiting resistor. Contact closure for a $28-\mathrm{V}$ relay (RY1) produces a brief train of square waves whenever the operate stud for RY1 is activated. The square wave is entered into the recorder (set to the record position) through $\mathrm{J} 1$ which is connected to the microphone input of the recorder. The contact closures supplied by RY1 are produced whenever the programming apparatus operates RY1; e.g., when a rat presses a lever.

The second jack (J2) is connected to the speaker (earphone) output of the recorder. When the cassette is played back, the recorded $60-\mathrm{Hz}$ signal is input to diodes D3 and D4 (IN4001) which trigger the TRIAC (Electronics Control Corp., Q2004). The TRIAC operates the relay (RY2) for the duration of the square wave pulse.

Requests for reprints should be sent to Allen H. Wolach, Department of Psychology, Illinois Institute of Technology. Chicago, Illinois 60616 .
A $120-\mathrm{V}$ relay can be used for RY2 if the output from the $110 . \mathrm{V}$ line is substituted for the $6.3 \mathrm{~V}$ obtained from $\mathrm{T} 1$ for the output circuit. The $110-\mathrm{V}$ line requires a TRIAC with a higher PRV than some TRIACs used with 6.3-V ac relays (the Q2004 operates well with a $110-\mathrm{V}$ relay).

Our present method for recording data is simple and inexpensive. Several relatively complicated and expensive procedures have been described for coding information that allow more than one channel of information to be recorded simultaneously on one channel of recording tape (e.g., Hopkins, 1972). The simplicity of our system would be compromised by adding a decoding system. It is possible to use recorders with more than one input (e.g., a stereo cassette recorder) and simultaneously record information on two or more channels. A separate converter must be constructed for each channel.

Cassette tapes are easier to store than cumulative records. If a variable speed drive is available for the cumulative recorder, interesting sections of a tape can be rerecorded at different paper speeds. It is also possible to code each tape with an audio signal. That is, the tape recorder microphone can be used for dictating subject number, session number, etc., at the beginning of each tape.

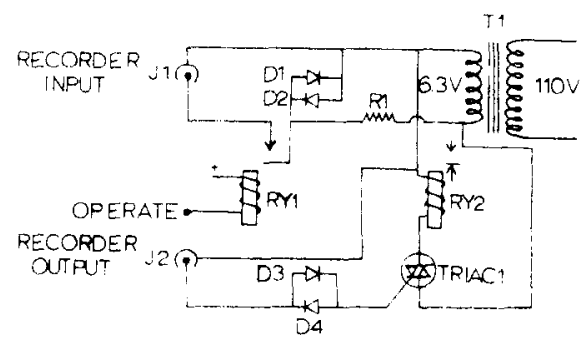

Figure 1. Converter for recording discrete pulses on tape and converting output from a tape recorder into a discrete relay closure. Diodes D1, D2, D3, and D4 are 1N4001. Transformer $\mathrm{T} 1$ is a step down transformer, 110-V primary, 6.3-V secondary at $1 \mathrm{~A} . \mathrm{R} 1$ is a $12,000-0 \mathrm{hm}$ resistor, RY1 is a relay with coil voltage that is the same voltage used with the programming rack. $R Y 2$ is a $6.3-\mathrm{V}$ relay (see text for substituting a $110-\mathrm{V}$ relay). The TRIAC (TRIAC1) is an Electronics Corp. Q2004. 
The recording system is also useful for yoked control studies. A subject's response pattern can be recorded and later the recorded presses can be played back and the output from RY2 can be used to program contingencies for a yoked control subject. This control procedure allows the experimenter to yoke as many subjects as necessary to a given experimental subject. After the cumulative record is produced for an experimental sub. ject, the paper can be rewound onto the spool in the cumulative recorder and data from a yoked control subject recorded on the same cumulative record.

The recording system can be used also for programming interval schedules. Procedurally, the record circuit is plugged into the tape recorder which is set to the "record" position. The experimenter activates the record relay (RYl) whenever an appropriate interval elapses, as indicated by a timer. Once the cassette information is recorded, it can be played back to operate RY2. This relay produces a contact closure that occurs after each recorded interval. The recorder can be stopped after each recorded interval by having RY2 fire a holding circuit (Dinsmoor, 1966, p. 440) whenever an interval elapses. The output relay from the holding circuit is used to disconnect one side of the tape recorder power supply. This stops all interval timing. The programming circuitry for the experiment can fire a pulse former (Dinsmoor, 1966, p. 442) that resets the holding circuit after an appropriate length of time, e.g., after a subject makes a lever press. The pulse former should have a signal that is longer than the recorded pulse. Figure 2 shows a block diagram for using the input-output converter as part of an interval schedule programmer.

The interval schedule programmer takes up less space than film programmers, costs less, and it is easier to pro-

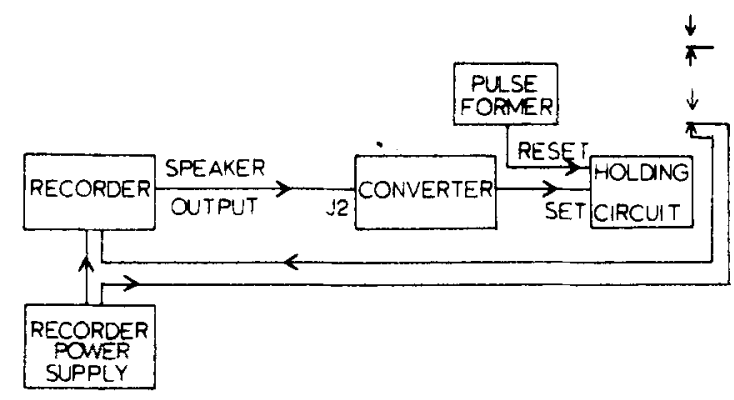

Figure 2. Block diagram for using a recorded tape for interval scheduling. The recorder speaker output is connected to the playback input (J2) of the converter. The relay output (RY2) for the converter activates a holding circuit (see text). The holding circuit disconnects one side of the tape recorder power supply, stopping the recorder. The pulse former (see text) resets the holding circuit and starts the recorder.

gram. A cassette tape is also less likely to break than a strip of film with punched holes. One disadvantage is that the tape must be rewound after a given number of subjects, depending on cassette length and session length. This disadvantage can be minimized by using cassettes that are recorded on both sides. The cassette can be rewound on the side that requires less rewinding.

\section{REFERENCES}

Dinsmoor, J. A. Operant psychology. In J. B. Sidowski (Ed.). Experimental methods and instrumentation in psychology. New York: McGraw-Hill, 1966.

Hopkins, R. H. A digital programmer for use with audio tape decks, Behavior Research Methods \& Instrumentation, 1972, 4, 317-319.

(Received for publication August 4, 1975; revision received October $5,1975$. 